\title{
The Importance of Understanding and Assessing for Financial Health in Older Adulthood
}

\author{
Carla Edwards* \\ Northwest Missouri State University, USA
}

Submission: April 14, 2017; Published: April 28, 2017

*Corresponding author: Carla Edwards, Northwest Missouri State University, MBA PhD PAS Advisors 4901 W 136th Street, Leawood, Kansas 66224, USA, Tel: 913-827-4107; Email: Carla@PASAdvisorsllc.com

\begin{abstract}
Healthy aging and prevention efforts for the elderly warrant attention in a world where the average mortality rate continues to increase. The current article addresses a gap in the psychological literature review related to the crossover between the clinical variables related to the aging adult and financial situations of those same older adults. Older adults who are living longer and healthier; as well as facing the physical and psychological challenges that come with extended life are also faced with a financial dilemma as retirement accounts run out before life's end. The research is unequivocal related to a path to positive aging; healthy lifestyle, social activities, utilizing social and environmental resources, and employing coping skills developed across the lifespan can enhance the quality of life for older adults. However, no psychological literature takes into account the financial resources needed to sustain this healthy and active lifestyle or the early financial planning necessary to ensure that quality of life. Professionals who work with this growing group, and recognize the resiliency factors inherent in healthy aging, need to understand the financial resources necessary for healthy aging. The purpose of the present article is twofold: l) To understand the potential effect of dwindling finances for older adults across older adulthood and 2) To review empirically supported interventions that can incorporate financial wellness as a part of the model.
\end{abstract}

Keywords: Aging, Gerontology; Aging, Retirement; Finances

\section{Introduction}

The number of aging adults, in our culture, is expanding exponentially with expectations of growth as high as $41 \%$ by 2041 in the United States [1,2]. This "graying of America" has implications across disciplines and settings for the health care industry and for businesses that serve this group [3]. Up until recently, most efforts to address the needs of this group were based on clinical health care issues that viewed retirement as a time of loss and disease [4,5]. This rapidly increasing demographic group will also contend with longevity that dictates making personal and financial resources last longer than many of them have planned for [6].

The variables, which enhance the experience of being older, outside of research in health care settings, is rare and does not consider an interdisciplinary approach to aging [3,7]. In addition, understanding how older adults face the years beyond their 80 's is sorely lacking in the literature; as is exploration of the implications of limited and dwindling financial resources predicted by financial advisors and investment managers [6]. In addition, very few researchers focus on how finances and financial planning interact with psychological variables and interventions to move older adults toward a positive retirement experience.

Many individuals over 65 have experienced wars, natural disaster, poor economic conditions, lower standards of living, and lack of available resources for a comfortable life as a part of their environment from the 1940s and 1950s. Valiant [8] even suggested that older adults who coped with more negative life events and lower income, in their early adult life, are better prepared than their children to cope with the challenges of older adulthood. Is it possible that the ability to cope with poverty or low income is a variable that predicts coping in older adulthood. If so, those who are used to a upper middle income or above and have not planned well for living past age 80 [6] may be facing life experiences that they have not encountered before.

Recent authors have suggested that community oriented, diverse, and enhanced services are important to healthy aging as the ability to meet the individual needs increases for an aging population $[9,10]$. The research in psychology coupled with the 
forecasts of financial planners and benefits managers suggests that community services, transportation services, residential care facilities, mental health services and health services available to older adults may not be affordable as social security incomes do not meet more than basic needs.

As dwindling investments and retirement accounts are outlived, this may be a dilemma for many middle class individuals who did not plan for current predictions of longevity. The true crises of the baby boomer's generation may begin soon, as predicted in the popular media, for those in lower income levels. Yet, its full impact may not be realized for many years as those in the middle and upper middle classes run out of investment based retirement funds. Environmental changes beyond the control of the older adult (e.g., crime increases, health problems, and changes available services) have been found to increase the tendency to isolate and reduce the activity level of older adults [11]. This suggests that older adults, who have not planned well for retirement, have a high likelihood of being forced to downsize and move to neighborhoods where service availability is limited and not within the parameters of the lifestyle they are accustomed to. Many may face, less safe neighborhoods than they have lived in all their lives.

In American culture aging and the idea of aging is put forward as a negative event to avoid, rather than a positive event to plan for. A failure to plan for the transition to retirement at both the psychological and financial levels can mean that socio-economic status interplays with social and institutional ageism contributing to heightened risk for depression, isolation, and avoidance of help seeking [3]. The interaction between geropsychiatric mental health issues and health issues is interwoven and complicated. When the cultural norm related to financial security is added to this picture, as a variable, the problems can grow exponentially related to both psychological and physical health. Wessell and Edwards [3] and Yassuda and Nunes [12] strongly assert that innovative and cross-disciplinary interventions could be effective in retirement counseling in older adulthood. It may be pertinent to include planning for older adulthood prior to reaching those late life crises. The inclusion of financial health is often neglected in psychological settings across disciplines and yet necessary to understanding and planning for development across the lifespan. In addition, the research addressing how helping professions can address this issue, is sorely missing from professional journals.

Overall the research strongly indicates that keeping older adults active and engaged in life activities seems essential not only to physical wellness, but for psychological well-being too [13]. However, life activities often involve transportation and financial resources [12]. Hintz [14] found that music and hobby focused activities can enhance nervous system functioning and assist in combating agitation for individuals in those who resist physical activity. Case Studies [6] have indicated that activities, such as horticultural are beneficial in increasing socialization, stimulating cognitive activity, and increasing physical activity for older adults. Music with activity has also been used successfully in enhancing later life satisfaction; in palliative care, in hospital settings, in community centers, in religious settings, and nursing homes in efforts to reduce pain perception, enhance positive affect, and increase coping skills $[15,16]$. Individualizing and strategizing to incorporate these activities into healthy aging must take into consideration the cost of activities and services and help the client plan for and realize a personally acceptable financial situation in older adulthood.

\section{Interventions}

In application, of recommended preventative directions, it is crucial for the practitioner and facilitator of preventative mental health to utilize strong models to guide and direct their work. The following models are models of prevention and intervention that give direction and the ability to plan appropriate preventative strategies for the older adult. These models are also flexible and allow for the inclusion of financial wellness as appropriate to the clients situation.

Lehr's (1977, p. 7) important description of geroprohylaxis, in outlining intervention directions appropriate in geropsychology, provides a foundation for describing various prevention and intervention strategies for enhancing the aging experience. Lehr suggests that the main focus of geropsychological interventions should:

a. Educate the older adults to a healthy lifestyle based on current intrinsic and extrinsic resources

b. Focus on the management of current stressors

c. Focus on adequate exercise and appropriate diet

d. Assist in maintaining autonomy

e. Address prevention of disease

Leer's model remains important forty years later; and the dearth of research reviewed herein continues to support this basic model of healthy strategies to enhance life into the later years.

Of note, a financial assessment for future needs and a review of probable expense needs for older adults is easily an adjunct to the Lear model in main focuses:

I. Related to intrinsic and extrinsic resources as the professional adds an assessment to understand savings, spending habits, and available resources for the client in the future.

II. In managing current stressorsas the professional seeks to understand how financial limitations or advantages contribute to the ability of the client to access important community services, health services, and personal activities.

III. In assistance of autonomy as the professional helps the client tap education and professional services, through 
referral, that will assist the client in money management and investment strategies.

Another model by Baltes [17] organizes the important focus of selective optimization with compensation.

The key to preventative and intervention efforts, in this model, is to clearly outline the individual's limitations and seek to enrich and augment reserves, optimizing the quality of life for the aging adult. Baltes also recognizes the importance in using new resources and external referrals to address limits that are identified by the helping professional. Related to this model, an assessment of the older adult's financial needs and resources as well as augmentationthrough referral are crucial to the success of intervention. Wagner's [18] Chronic Care Model (CCM) has been used widely and has sturdy empirical support. The model predicts that improvement in the interrelated areas of selfmanagement, support, clinical system redesign, and decision support activates individuals to be prepared and proactively address health and mental health issues in older adulthood. Assessing, reviewing, and referring to community resources and professionals in the area of financial management easily fits the criteria of this model.

Leventhal, Rabin, Leventhal, and Burn's [19] model, of "SelfRegulation" as intervention, for the elderly suggests that any model of effective intervention includes:

a. Increasing motivation and decreasing barriers to intervention

b. A plan for change that matches current life situation

c. Evidence that other adults improve functioning based on the planned interventions

d. Addressing environmental supports and barriers to intervention.

Related to the Leaventhal et al. [19] model, ascertaining financial status of the older adult is important to understanding barriers to intervention, access to services, sustaining current life situations at a high level, and planning interventions. An increase in life expectancy is permitting older adults to live longer-and healthier longer. This is creating a situation which stands to be a heavy burden on health care cost and the economy, placing a great importance on prevention and intervention efforts for this developmental cohort. Helping older adults support themselves and personally finance life activities is important to our society at large; as well as to the aging adult. Research needs to point itself toward preventative strategies and their significant impact on healthy aging which must include an assessment of financial well-being, as well as psychological and physiological well-being.

Professionals working with older adults should understand when referral to money management professionals is warranted. By using models of prevention that address key issues of healthy aging and includes an assessment of financial health, the professional comes to understand the need for adjunctive services in the area of finance. This suggested integrative approach to prevention efforts with older adults relies heavily on the assumption that more in depth and cross-disciplinary research and practice in collaboration with professionals in finance is important. Several other areas of further research are suggested including a focus on financial needs of older adults, financial assessment as an ancillary of biopsychosocial evaluations, and integration of financial topics into already existing models of care. The need for this research and application in the field will enable the "greying of America" to stand on positive and empirically sound prevention efforts, that are enhanced by more holistic and interdisciplinary knowledge, long into the future.

\section{References}

1. DeVaus D, Wolcott I (1997) Australian family profiles: social and demographic patterns. Australian Institute of Family Studies, Melbourne, Australia 51: S33-S44.

2. Snarski M, Scogin F, DiNapoli E, Presnell A, McAlpine J, et al. (2010) The effects of behavioral activation therapy with inpatient geriatric psychiatry patients. Behav The 42(1): 100-108.

3. Wessell R, Edwards C (2012) Principles of longevity and aging: Interventions to enhance older adulthood. Journal of Educational and Developmental Psychology 2(1): 108-120.

4. Alexopoulos GS, Raue P, Areån P (2003) Problem-solving therapy versus supportive therapy in geriatric major depression with executive dysfunction. Am J Geriatr Psychiatry 11(1): 46-52.

5. Nebes RD, Butters MA, Mulsant BH, Pollock BG, Zmuda MD, et al. (2000) Decreased working memory and processing speed mediate cognitive impairment in geriatric depression. Psychol Med 30(3): 679-691.

6. Hung L, Kempen GI, DeVries NK (2010) Cross-cultural comparison between academic and lay views of healthy aging: literature review. Aging and Society 30(8): 1372-1391.

7. Vaillant G (1993) The Wisdom of the Ego. Harvard University Press, Cambridge, USA.

8. Ejogu N, Norbeck JH, Mason MA, Cromwell BC, Zonderman AB, et al. (2011) Recruitment and retention strategies for minority or poor clinical research participants: lessons from the healthy aging in neighborhoods of diversity across the life span study. Gerontologist 51(1): S33-S45.

9. Saarloos D, Alfonso H, Giles-Corti B, Middleton N, Almeida O (2011) The built environment and depression in later life: The health in men study. Am J Geriatr Psychiatry 19(5): 461-470.

10. Thompson EE, Krause N (1998) Living alone and neighborhood characteristics as predictors of social support in late life. J Gerontol B Psychol Sci Soc Sci 53(6): S354-S364.

11. Yassuda MS, Nunes PV (2009) Innovative psychosocial approaches in old age psychiatry. Curr Opin Psychiatry 22(6): 527-531.

12. Rowan NL, Gillette PD, Fault AC, Yankeelov PA, Borders KW, et al. (2009) Innovative interdisciplinary training in and delivery of evidence-based geriatric services: Creating a bridge with social work and physical therapy. Gerontol Geriatr Educ 30(3): 187-204.

13. Hintz MR (2000) Geriatric music therapy clinical assessment: Assessment of music skills and related behaviors. Music Therapy Perspectives 18(1): 31-40. 
14. McGuire DL (1997) Implementing horticultural therapy into a geriatric long-term care facility. Activities, Adaptation \& Aging 22(1-2): 61-81.

15. Ledger AJ, Baker FA (2007) An investigation of long-term effects of group music therapy on agitation levels of people with Alzheimer's Disease. Aging Ment Health 11(3): 330-338.

16. Myskja A, Nord PG (2008) The day the music died': A pilot study on music and depression in a nursing home. Nordic Journal of Music Therapy, pp. 30-40.

This work is licensed under Creative

Commons Attribution 4.0 License

DOI:10.19080/PBSIJ.2017.3.555619
17. Baltes PB (1997) On the incomplete architecture of human ontogeny: Selection, optimization, and compensation as foundation of developmental theory. Am Psychol 52(4): 366-380.

18. Wagner EH (1998) Chronic disease management: What will it take to improve care for chronic illness? Eff Clin Pract 1(1): 2-4.

19. Leventhal H, Rabin C, Leventhal EA, Bums E (2001) Health risk behaviors and aging. The Psychology of Aging 5: 186-213.

Your next submission with Juniper Publishers will reach you the below assets

- Quality Editorial service

- Swift Peer Review

- Reprints availability

- E-prints Service

- Manuscript Podcast for convenient understanding

- Global attainment for your research

- Manuscript accessibility in different formats ( Pdf, E-pub, Full Text, Audio)

- Unceasing customer service

Track the below URL for one-step submission https://juniperpublishers.com/online-submission.php 